\title{
Active surveillance for low-risk prostate cancer compared with immediate treatment: a Canadian cost comparison
}

\author{
Alice Dragomir PhD, Fabio L. Cury MD, Armen G. Aprikian MD
}

Abstract

Background: Clinical consequences of active surveillance compared with immediate treatment have been evaluated in patients with low-risk prostate cancer; yet, its financial benefits have not been adequately studied in Canada or elsewhere. Our study objective was to evaluate the direct costs associated with active surveillance and immediate treatment in the Canadian context.

Methods: We developed a Markov model with Monte Carlo microsimulations to estimate the Canadian cost of prostate cancer associated with immediate treatment and active surveillance strategies. The patients receiving active surveillance were assumed to receive delayed treatment at a rate of $8.35 \%, 4.17 \%$ and $2.1 \%$ per year for the first 2 years, years 3 to 5 , and years 6 to 10 of follow-up, respectively. All costs were assigned in Canadian dollars and reflect Quebec's health system.

Results: With active surveillance, the mean cost of prostate cancer management over the first year and 5 years of follow-up was estimated at \$6200 (95\% confidence interval [Cl] \$6083-\$6317) per patient. The mean cost corresponding to immediate treatment was estimated at $\$ 13735$ (95\% Cl \$13 615-\$13 855) per patient. We estimated that patients receiving active surveillance who received delayed treatment incurred higher costs of $\$ 16257$ per patient.

Interpretation: Active surveillance could offer important economic benefits to the Canadian health system, estimated at $\$ 96.1$ million for each annual cohort of incident prostate cancer. These results add to the economic rationale advocating active surveillance for eligible men with low-risk prostate cancer.

$\mathrm{P}$ rostate cancer is the most common cancer and the third leading cause of cancer-related mortality in Canadian men. In Canadian Cancer Statistics 2011, an incidence of 122 per 100000 person-years was reported, which is twice the incidence of lung or colorectal cancer, respectively the second and third leading causes of cancer. ${ }^{1}$ Whereas the incidence of colorectal cancer has been stable over the last 30 years, the incidence of prostate cancer has increased by $50 \%$. Correspondingly, the economic burden of prostate cancer is also very high in Canada and elsewhere..$^{2-6}$

Studies have shown that most cancers at diagnosis are low to intermediate risk. ${ }^{78}$ The natural history of prostate cancer is variable, but many cancers, especially the low-risk category, may be considered indolent and may not require immediate treatment. Active surveillance ${ }^{9}$ with delayed treatment is one of the accepted alternatives to immediate treatment for lowrisk cancers. ${ }^{7,10,11}$ Active surveillance presents several advantages, especially for older men and for those with low life expectancy, but also for those with good life expectancy for whom active surveillance may allow the preservation of quality of life compared with immediate treatment. ${ }^{12-14}$ One study has shown that when quality of life associated with the clinical discomfort of initial treatment and the psychological discomfort of living under active surveillance were taken into consid- eration, the quality-adjusted life expectancy (QALE) was greater for active surveillance (11.07 QALE) than for brachytherapy (10.57 QALE), intensity-modulated radiotherapy (10.51 QALE) and radical prostatectomy (10.23 QALE). ${ }^{15}$ In addition, a second study has shown that in a group of lowrisk patients aged 70 years, the initial treatment with radiotherapy had an advantage of about 0.4 QALE compared with watchful waiting, ${ }^{16}$ but no benefit in the case of radical prostatectomy (9.4 QALE for both radical prostatectomy and watchful waiting). Despite published guideline recommendations, ${ }^{9,17}$ overtreatment of prostate cancer is common in the United States and elsewhere, with about $70 \%$ to $90 \%$ of patients undergoing immediate treatment. ${ }^{18,19}$ In Canada, about $75 \%$ of patients with prostate cancer have received immediate treatment from 1995 through $2002 .^{20} \mathrm{It}$ is believed today that more than half of these patients did not require

Competing interests: None declared.

This article has been peer reviewed.

Correspondence to: Alice Dragomir, alice.dragomir@muhc.mcgill.ca CMAJ Open 2014.DOI:10.9778/cmajo.20130037 
immediate treatment at the time of diagnosis, but the treatments led to cost and morbidity. ${ }^{21,22}$

The costs of active surveillance with delayed treatment compared with the costs of immediate treatment were recently evaluated from the perspective of the US health care system by Keegan and colleagues. ${ }^{23}$ The corresponding estimates in the Canadian context of universal health care are unknown. Despite the fact that clinical practice for prostate cancer is similar in the US and Canada, the cost of health care services is likely to differ between the countries. In addition, the US model did not take into consideration mortality and recurrence of prostate cancer, ${ }^{23}$ which are elements that could substantially affect the percentage of patients requiring treatment and cost estimates, especially on a long-term basis.

The primary objective of this study was to develop a model to estimate the direct cost associated with active surveillance and immediate treatment for low-risk prostate cancer in Canada. This model accounted for the rate of disease progression requiring delayed treatment, overall mortality, and disease recurrence requiring additional treatment, in the context of the public health care system in Quebec. The second objective was to compare Canadian and US cost estimates.

\section{Methods}

\section{Modelling assumptions}

We developed a Markov model with Monte Carlo microsimulations to simulate the management of low-risk prostate cancer and cost over the first year, 5 years and 10 years of followup, accounting for the rate of death and disease recurrence or progression. We modelled 2 alternative management strategies: active surveillance with delayed treatment, and immediate treatment. The Markov model is a state transition model with a cycle length of 1 year; Figure 1A shows the strategy of immediate treatment, and Figure $1 \mathrm{~B}$ presents the strategy where patients initially receive active surveillance and can receive delayed treatment. As Figure 1 shows, the patients receiving active surveillance were assumed to receive delayed treatment at a rate of $8.35 \%, 4.17 \%$ and $2.1 \%$ per year for the first 2 years, years 3 to 5 , and years 6 to 10 of follow-up, respectively. The 5 health states defined in relation to immediate treatment options are as follows: radical prostatectomy, intensity-modulated radiotherapy, brachytherapy, androgen deprivation therapy, and intensity-modulated radiotherapy plus androgen deprivation therapy for 6 months. We derived the models' assumptions from a Canadian study involving an active surveillance cohort. ${ }^{11}$

\section{Cost assignments}

All direct costs were assigned in 2012 Canadian dollars and estimated from the 2012 perspective of the public health care system in Quebec. The cost of active surveillance and treatments were categorized into the following: initial cost assigned in the first year, and follow-up cost assigned over the following 5-and 10-year periods. The disease-related method $^{24}$ has been used to estimate costs of treatments and active surveillance. The cost components and the quantities of resources used were based on specific protocols used at the McGill University Health Centre; however, these protocols are similar to those described by Keegan and colleagues. ${ }^{23}$ The cost components, unit costs and sources are presented in Table $1 .^{25-29}$ We estimated the cost of treatments and active surveillance by summing the quantities of resources used and multiplying by the unit cost of each cost component. The active surveillance protocol was derived from Klotz and colleagues. ${ }^{11}$ This consists of the following: (1) a prostate-specific antigen test performed every 3 months for 2 years and then every 6 months in stable patients; and (2) initial biopsy and confirmatory biopsy performed 6 to 12 months after the initial biopsy, and then every 3 to 4 years. To reflect the time value of money, we used a standard discount rate of $5 \% .^{30}$

\section{Statistical analysis}

\section{Cost analyses}

With a more than $50 \%$ rate of low-risk prostate cancer at diagnosis $^{7,8}$ and based on the 2011 Canadian incidence of prostate cancer, ${ }^{1}$ we estimated about 12750 patients as potential candidates for active surveillance. We simulated the disease management and associated cost of 12750 incident patients, initially receiving active surveillance or assigned to immediate treatment, over the first year and 5 and 10 years of follow-up by applying the corresponding Markov models (Figure 1). The mean cost per patient is the mean of individual cost estimations obtained with Monte Carlo microsimulations.

\section{Sensitivity analysis}

To compare our Canadian cost estimates with US cost estimates, we changed our Markov model to reflect assumptions derived from Keegan and colleagues. ${ }^{23}$ We considered a discount rate of $3 \%$ and $10 \%$. To estimate whether the cost difference between active surveillance and immediate treatment strategies was maintained over a longer period, we modelled a 15-year period of follow-up by assuming mortality after 10 years of follow-up of $8.16 \%$ per year. This rate corresponds to the Statistics Canada estimate for the general population aged 75 and older, which is the age category of the simulated incident cases after 10 years of follow-up. Finally, we assumed that $40 \%$ and $60 \%$ of yearly incident cases are eligible for active surveillance, which yielded a number of 10200 and 15300 patients, respectively.

\section{Results}

\section{Cost of active surveillance and treatment}

Initial and 5-year follow-up costs specific to each treatment are presented in Table 2. Radical prostatectomy and brachytherapy were the treatments with the lowest initial cost (\$7428 and $\$ 8455$, respectively), and the intensity-modulated radiotherapy plus androgen deprivation therapy was the intervention with the highest cost, estimated at $\$ 14444$. In contrast, the androgen deprivation therapy was the treatment with the highest cost over the 5-year follow-up period, estimated at \$23 202. These estimates were all higher than the initial and 5-year 


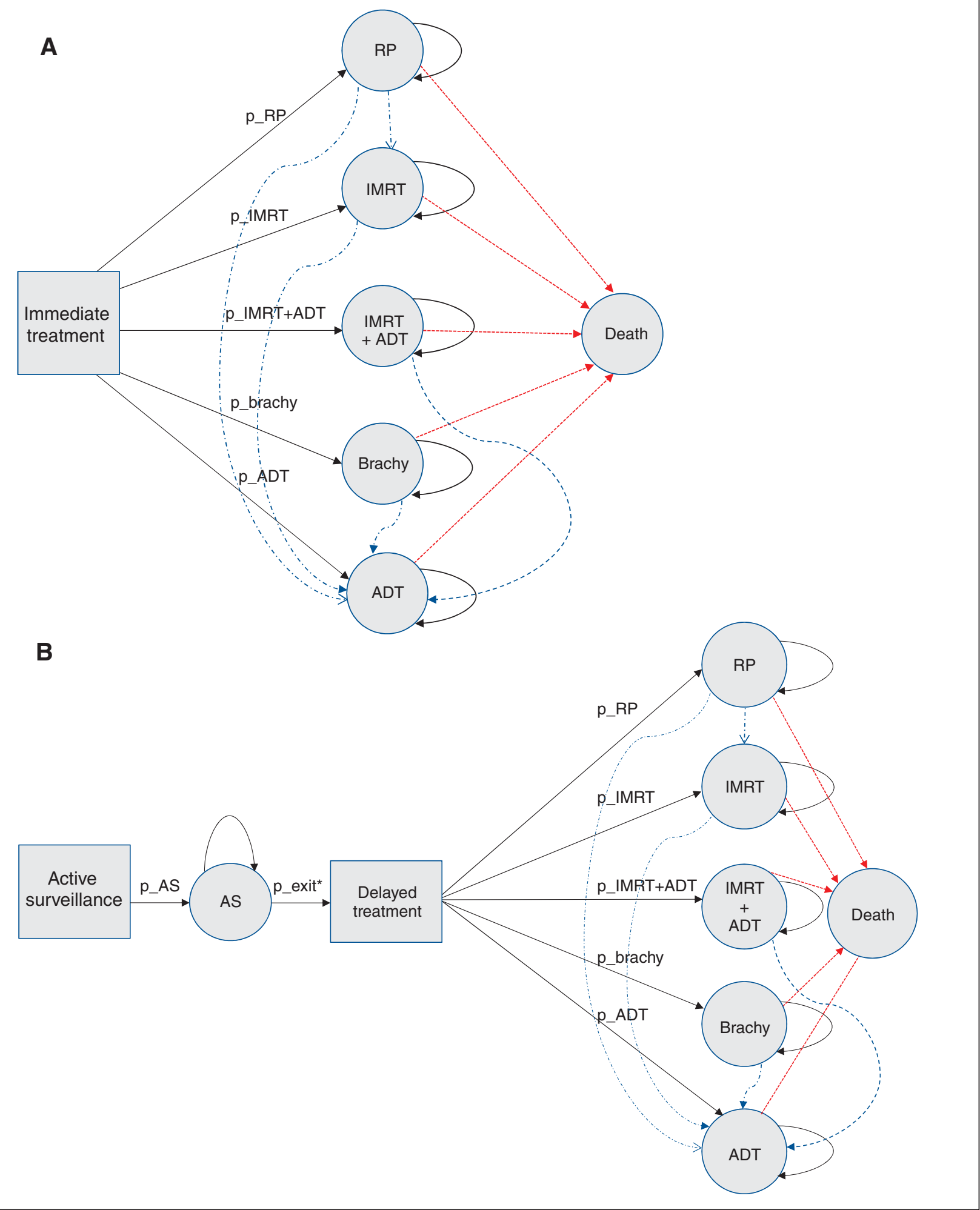

Figure 1: Markov models with transition to death (red lines) and recurrence requiring additional treatment (blue lines) for (A) immediate treatment and (B) active surveillance. Note: ADT = androgen deprivation therapy, Brachy = brachytherapy, IMRT = intensity-modulated radiotherapy, p_ADT $=$ probability of receiving ADT, $p \_A S=$ probability of receiving active surveillance, $p \_$Brachy = probability of receiving brachytherapy, p_IMRT = probability of receiving IMRT, p_IMRT+ADT = probability of receiving IMRT + ADT, p_RP = probability of receiving radical prostatectomy, $\mathrm{RP}=$ radical prostatectomy. ${ }^{*} \mathrm{p} \_$exit $=$yearly rate of switch to active treatment, 0.0835 (yr 1 and 2 of follow-up), 0.0417 (yr 3 to 5 of followup) and 0.021 (yr 6 to 10 of follow-up). ${ }^{11}$ Note: The following values were used in the Markov models: $p \_A S=1, p \_R P=0.26, p \_I M R T=0.34$, p_IMRT+ADT $=0.13, p \_B r a c h y=0.20, p \_A D T=0.074,1$-year probability of death $=0.038 ; 1$-year probability of recurrence requiring additional treatment $=0.139$ for active surveillance and 0.0257 for immediate treatment. ${ }^{11}$ 
follow-up cost of active surveillance, estimated at \$1224 and $\$ 1767$, respectively.

\section{Treatment course and associated costs}

At the end of 5 years of follow-up, with the use of the Markov model we estimated $2805(22.0 \%)$ patients having received delayed treatment, $442(3.5 \%)$ having received delayed treatment and having died, 2205 (17.3\%) having died while receiving active surveillance and 7298 (57.2\%) still receiving active surveillance. The corresponding rates after 10 years were as follows: 2938 (23.0\%) of patients having received delayed treatment, $984(7.7 \%)$ having received delayed treatment and

Table 1: Cost components and unit costs related to management of prostate cancer (2012 Canadian dollars)

$\begin{array}{lll}\text { Cost components } & \text { Cost per unit, } \$ & \text { Source }\end{array}$

\section{Component 1}

\begin{tabular}{lrl} 
Initial office consultation, urology & 77 & ${\text { RAMQ } \ddagger \text { list }^{25}}^{25}$ \\
\hline Initial office consultation, radiation oncology & 133 & ${\text { RAMQ } \text { list }^{25}}^{\text {Component } 2}$ \\
\hline Urologist reimbursement for prostate biopsy & 78 & ${\text { RAMQ } \ddagger \text { list }^{25}}^{25}$ \\
\hline Prostate biopsy (based on 12-sample needle core) & & \\
\hline Pathology & 158 & MUHC: unpublished data, 2012 \\
\hline Professional and technical fees & 183 & MUHC: unpublished data, 2012 \\
\hline
\end{tabular}

Prostate analysis after surgery (prostatectomy with obturator lymph nodes)

\begin{tabular}{|c|c|c|}
\hline Pathology & 204 & MUHC: unpublished data, 2012 \\
\hline Professional and technical fees & 640 & MUHC: unpublished data, 2012 \\
\hline PSA test & 11 & MUHC: unpublished data, 2012 \\
\hline \multicolumn{3}{|l|}{ Component 3} \\
\hline Office visits, urology & 59 & RAMQ $\neq$ list $^{25}$ \\
\hline Office visits, radiation oncology & 44 & RAMQ $\ddagger$ list $^{25}$ \\
\hline Urologist reimbursement for radical prostatectomy & 922 & RAMQ $\ddagger$ list $^{25}$ \\
\hline \multicolumn{3}{|l|}{ Radiation oncologist reimbursement for radiotherapy } \\
\hline Computed tomography planning and IGRT plan & 1010 & RAMQ‡ list ${ }^{25}$ \\
\hline $\begin{array}{l}\text { Intensity-modulated radiotherapy session (includes office } \\
\text { visit, image fusion and checking) }\end{array}$ & 81 & RAMQ $\ddagger$ list ${ }^{25}$ \\
\hline $\begin{array}{l}\text { Dose planning, ultrasonography guidance and interstitial } \\
\text { implant (brachytherapy) }\end{array}$ & 735 & RAMQ $\ddagger$ list $^{25}$ \\
\hline \multicolumn{3}{|l|}{ Component 4} \\
\hline Medication costs (goserelin acetate implant every $3 \mathrm{mo}$ ) & 1088 & RAMQ‡ list ${ }^{26}$ \\
\hline Nursing (average salary/mo) & 6667 & MUHC: unpublished data, 2012 \\
\hline \multicolumn{3}{|l|}{ Component 5} \\
\hline Surgical procedure* & 4547 & $\begin{array}{l}\text { Ministère de la Santé et des Services sociaux; }{ }^{27} \\
\text { Ministère de la Santé et des Services sociaux: } \\
\text { unpublished data, } 2012 \S\end{array}$ \\
\hline $\begin{array}{l}\text { Brachytherapy procedure (palladium-103) including seeds } \\
\text { cost }^{*}\end{array}$ & 6700 & CETS; ${ }^{28}$ Canadian Patient Cost Database ${ }^{29}$ \\
\hline Intensity-modulated radiotherapy procedure $†$ & 7402 & MUHC: unpublished data, 2012 \\
\hline \multicolumn{3}{|l|}{ Component 6} \\
\hline Anesthesia for surgery & 650 & MUHC: unpublished data, 2012 \\
\hline Anesthesia for brachytherapy & 250 & MUHC: unpublished data, 2012 \\
\hline \multicolumn{3}{|c|}{$\begin{array}{l}\text { Note: CETS = Conseil d'évaluation des technologies de la santé du Québec, IGRT = image-guided radiotherapy, MUHC = McGill University Health Centre, PSA = prostate- } \\
\text { specific antigen, RAMQ = Régie de l'assurance maladie du Québec. } \\
\text { "This amount includes intervention, nursing care, diagnosis and therapeutic services. } \\
\text { tIncludes cost of dosimetry (radiotherapist, planning system and information system), physics quality assurance (physicist, physics associates, specialized quality } \\
\text { assurance equipment, planning system and information system) and treatment preparation and delivery (radiotherapy, linear accelerator, nurse, information system) } \\
\text { equivalent of } 38 \text { fractions. This value does not include overheads. } \\
\text { †The administrator of the public and universal health care insurance program in Quebec. The costs of medical procedures related to treatments and medical visit costs } \\
\text { were based on the RAMQ's billing manual, }{ }^{25} \text { and the costs of medications were based on the RAMQ's list of medications approved for public reimbursement. }{ }^{26} \\
\text { §Details on collected variables can be found in Performance hospitalière (APR-DRG [J57]). } .^{27}\end{array}$} \\
\hline
\end{tabular}


having died, 3454 (27.1\%) having died while receiving active surveillance and 5374 (42.1\%) still receiving active surveillance.

The cost per patient over the first year and 5 years of follow-up was estimated at \$13 735 (95\% CI \$13 615-\$13 855) for immediate treatment and \$6200 (95\% CI \$6083-\$6317) for active surveillance (Table 3 ). The cost associated with recurrence accounted for $\$ 1589$ and $\$ 1558$, respectively, of these costs. With a $5 \%$ discount rate, these figures were $\$ 13$ 166 (95\% CI \$12 966-\$13 165) and \$5515 (95\% CI \$5413$\$ 5619)$, respectively, corresponding to a relative reduction of $57.8 \%$. The 10-year follow-up period showed that the absolute cost benefits observed in the previous period were maintained at the end of this period.

We estimated that patients continuing to receive active surveillance over the 5 -year period of follow-up would incur a mean cost of \$2764 compared with \$16 257 in the group of patients receiving delayed treatment. Depending on the type of treatment, this cost varied from \$12 821 (95\% CI \$12 452$\$ 13190)$ per patient having received surgery or $\$ 14512$ (95\% CI \$14 046-\$14 973) per patient having received brachytherapy, to \$20 377 (95\% CI \$19 826-\$20 927) per patient having received intensity-modulated radiotherapy plus androgen deprivation therapy. The estimated cost associated with the recurrence accounted for $25 \%, 28 \%$ and $19 \%$, respectively, of these costs. Furthermore, delaying androgen deprivation therapy would allow important savings over immediate treatment, estimated at $\$ 4000$ per patient per year.

Furthermore, over the 10 years of follow-up, the lowest mean cost was still observed in the group of patients having received surgery (\$20 935, 95\% CI \$20 117-\$21 753) or brachytherapy (\$23 401, 95\% CI \$22 421-\$24 382). However, highest cost was estimated for patients having received androgen deprivation therapy (\$30 524, 95\% CI \$28 813-\$32 236).

\section{Total cost estimation}

The overall cost savings attributable to active surveillance over the first year and 5 years of follow-up was estimated at $\$ 96.1$ million (Table 4). This value is explained by a total savings of $\$ 104.4$ million obtained by avoiding treatment in $17.3 \%$ of patients who never required treatment and died from causes other than prostate cancer, and $57.2 \%$ of patients still receiving active surveillance, and a supplementary cost of $\$ 8.2$ million (equivalent to $\$ 500 /$ patient per yr) for delaying treatment for $25.5 \%$ of patients. When the rate of patients eligible for active surveillance was set to $40 \%$ and $60 \%$, estimated total costs were $\$ 76.9$ million, and $\$ 115.3$ million, respectively (data not shown). Similar values were observed over 10 years of followup, with an overall cost savings of $\$ 99.5$ million (Table 4).

\section{Sensitivity analysis}

The results of the sensitivity analysis are presented in Table 5. First, the model integrating assumptions from Keegan and colleagues $^{23}$ has simulated that $30 \%$ of patients receiving active surveillance have received delayed treatment after 5 years of follow-up, and $45 \%$ after 10 years of follow-up. The corresponding cost over the first year and a 5-year period of followup was \$12 712 (95\% CI \$12 161-\$12 381) per patient receiving immediate treatment, and \$5855 (95\% CI \$5780-\$5930) per patient receiving active surveillance. Thus, the mean cost savings attributable to the active surveillance strategy was $\$ 6416$, corresponding to a relative reduction of $52.3 \%$ from the cost of immediate treatment. In addition, similar trends have been observed between US cost estimates ${ }^{23}$ and Canadian estimates with respect to the number of years of active surveillance (Appendix 1 available at www.cmajopen.ca/content/2/2 /E60/suppl/DC1). With the exception of androgen deprivation therapy, delayed treatment is associated with an estimated increase of treatment cost between $3.3 \%$ and $6.7 \%$ per year (data not shown). Second, the sensitivity analyses performed with various discount rates have shown high consistency with the primary results. Finally, the model simulating 15 years of follow-up counts 2297 (18.0\%) patients having received delayed treatment, $2102(16.5 \%)$ having received delayed treatment and having died, 5259 (41.2\%) having died while receiving active surveillance, and 3092 (24.3\%) still receiving active surveillance at the end of this period. Furthermore, active surveillance was associated with a cost reduction of $\$ 7000$ to $\$ 8000$ per patient when compared with immediate treatment.

\section{Interpretation}

Our study demonstrates that for eligible patients, active surveillance could offer economic benefits to the health care system. At the national level, the overall cost savings of an

\begin{tabular}{|lrr|}
\hline Table 2: Initial and 5-year cost of treatment and active surveillance (2012 Canadian dollars) \\
\hline \multirow{2}{*}{ Treatment type } & \multicolumn{2}{c|}{ Cost, \$ } \\
\cline { 2 - 3 } & Initial & 5-year follow-up \\
\hline Active surveillance & 1224 & 1767 \\
\hline Radical prostatectomy & 7428 & 929 \\
\hline Intensity-modulated radiotherapy & 12261 & 618 \\
\hline Intensity-modulated radiotherapy and androgen deprivation therapy* & 14444 & 618 \\
\hline Brachytherapy & 8455 & 618 \\
\hline Primary androgen deprivation therapy & 5136 & 23202 \\
\hline *For 6 months. & & \\
\hline
\end{tabular}


annual cohort of incident prostate cancers managed with active surveillance over a first year and 5 years of follow-up was substantial. The cost savings are explained by the low cost of active surveillance in Quebec, the avoidance of the high cost of treatment for about three-quarters of eligible patients, and a minimal additional cost related to delayed treatment for one-quarter of the patients, estimated at $\$ 500$ per patient per year. In addition, these cost benefits could be maintained over a longer period of 10 to 15 years of followup. At the end of the 15-year period, we estimated that onequarter of patients would still be receiving active surveil- lance. These patients would likely be 80 years or older, and would likely cease active surveillance or no longer be eligible for treatment.

The US cost estimates ${ }^{23}$ are higher than Canadian estimates but similar trends were observed for specific treatments in relation to the number of years of active surveillance, and treatment delay, respectively (Appendix 1 available at www.cmajopen.ca/content/2/2/E60/suppl/DC1). Whereas the mean cost of surgery, brachytherapy, intensity-modulated radiotherapy, and intensity-modulated radiotherapy plus androgen deprivation therapy is slightly increased with each

Table 3: Cost estimates for active surveillance and immediate treatment over the first year and 5 to 10 years of follow-up

\begin{tabular}{|c|c|c|c|c|c|c|}
\hline $\begin{array}{l}\text { Period of follow-up; } \\
\text { strategy }\end{array}$ & \multicolumn{3}{|c|}{$\%$} & Mean cost per patient $(95 \% \mathrm{Cl}) \dagger, \$$ & \multicolumn{2}{|c|}{$\begin{array}{c}\text { Cost difference } \\
\text { (immediate treatment v. } \\
\text { active surveillance) }\end{array}$} \\
\hline \multicolumn{7}{|c|}{ First year and 5-year follow-up } \\
\hline Active surveillance & 3.8 & 13.9 & - & $6200 \quad$ (6 083-6 317) & 7535 & 54.9 \\
\hline \multirow[t]{2}{*}{ Immediate treatment } & 3.8 & 2.57 & - & 13735 (13 615-13 855) & & \\
\hline & 3.8 & 2.57 & 5 & 13166 (12 966-13 165) & & \\
\hline \multicolumn{7}{|c|}{ First year and 10-year follow-up } \\
\hline \multirow[t]{2}{*}{ Active surveillance } & 3.8 & 13.9 & - & 10600 (10 377-10 822) & 7808 & 42.4 \\
\hline & 3.8 & 13.9 & 5 & $8484 \quad$ (8 313-8 654) & 7755 & 47.8 \\
\hline
\end{tabular}

Table 4: Total cost for active surveillance and immediate treatment and possible cost savings corresponding to an annual cohort of 12750 patients with prostate cancer stratified by patients' treatment status

\begin{tabular}{|c|c|c|c|c|c|c|c|}
\hline \multirow[b]{2}{*}{ Treatment status } & \multirow[b]{2}{*}{$\%$ (no.) of patients } & \multicolumn{2}{|c|}{ Mean cost per patient, $\$$} & \multicolumn{2}{|c|}{ Total cost, \$ } & \multicolumn{2}{|c|}{ Cost difference, $\$$} \\
\hline & & $\begin{array}{c}\text { Active } \\
\text { surveillance }\end{array}$ & $\begin{array}{l}\text { Immediate } \\
\text { treatment }\end{array}$ & $\begin{array}{c}\text { Active } \\
\text { surveillance }\end{array}$ & $\begin{array}{l}\text { Immediate } \\
\text { treatment }\end{array}$ & Per patient & Total \\
\hline \multicolumn{8}{|c|}{ First year and 5-year follow-up } \\
\hline $\begin{array}{l}\text { Patients requiring } \\
\text { treatment }\end{array}$ & $25.5 \quad$ (3 247) & 16257 & 13735 & 52786479 & 44597545 & 2522 & $8188934^{*}$ \\
\hline $\begin{array}{l}\text { Patients not } \\
\text { requiring treatment }\end{array}$ & $74.5 \quad(9503)$ & 2753 & 13735 & 26161759 & 130523705 & -10982 & $-104361946 \dagger$ \\
\hline Total & $100.0(12750)$ & 6200 & 13735 & 79050000 & 175121250 & -7535 & $-96071250 \ddagger$ \\
\hline \multicolumn{8}{|c|}{ First year and 10-year follow-up } \\
\hline $\begin{array}{l}\text { Patients requiring } \\
\text { treatment }\end{array}$ & $30.8 \quad$ (3 922) & 25552 & 18407 & 100214944 & 72192254 & 7145 & $28022690^{*}$ \\
\hline $\begin{array}{l}\text { Patients not } \\
\text { requiring treatment }\end{array}$ & 69.2 (8 828) & 3959 & 18407 & 34950052 & 162496996 & -14448 & $-127546944 \dagger$ \\
\hline Total & $100.0(12750)$ & 10600 & 18407 & 135150000 & 234689250 & -7807 & -99 $539250 \ddagger$ \\
\hline
\end{tabular}




\begin{tabular}{|c|c|c|c|c|c|c|}
\hline \multirow[b]{2}{*}{ Period of follow-up; strategy } & \multicolumn{3}{|c|}{$\%$} & \multirow{2}{*}{$\begin{array}{l}\text { Mean cost per patient } \\
(95 \% \mathrm{Cl}), \dagger \$\end{array}$} & \multicolumn{2}{|c|}{$\begin{array}{c}\text { Cost difference (immediate } \\
\text { treatment v. active } \\
\text { surveillance) }\end{array}$} \\
\hline & Mortality* & Recurrence* & Discount $^{*}$ & & Absolute, \$ & Relative, \% \\
\hline \multicolumn{7}{|l|}{$\begin{array}{l}\text { Model integrating } \\
\text { assumptions derived from } \\
\text { Keegan et al. }{ }^{23} \ddagger\end{array}$} \\
\hline \multicolumn{7}{|l|}{ First year and 5-year follow-up } \\
\hline \multirow[t]{2}{*}{ Active surveillance } & 0 & 0 & - & $5855 \quad(5780-5$ 930) & 6416 & 52.3 \\
\hline & 0 & 0 & 5 & $5474 \quad(5408-5$ 539) & 6237 & 53.3 \\
\hline \multirow[t]{2}{*}{ Immediate treatment } & 0 & 0 & - & $12271(12$ 161-12 381) & & \\
\hline & 0 & 0 & 5 & $11711(11625-11798)$ & & \\
\hline \multicolumn{7}{|l|}{ First year and 10-year follow-up } \\
\hline \multirow[t]{2}{*}{ Active surveillance } & 0 & 0 & - & $9201 \quad$ (9 069-9 334) & 5843 & 38.8 \\
\hline & 0 & 0 & 5 & $7673 \quad(7584-7$ 763) & 6165 & 44.6 \\
\hline \multirow[t]{2}{*}{ Immediate treatment } & 0 & 0 & - & 15044 (14 806-15 282) & & \\
\hline & 0 & 0 & 5 & 13838 (13 679-13 997) & & \\
\hline \multicolumn{7}{|l|}{$\begin{array}{l}\text { Model with discount rates of } \\
3 \% \text { and } 10 \%\end{array}$} \\
\hline \multicolumn{7}{|l|}{ First year and 5-year follow-up } \\
\hline \multirow[t]{2}{*}{ Active surveillance } & 3.8 & 13.9 & 3 & $5810 \quad(5701-5920)$ & 7496 & 56.3 \\
\hline & 3.8 & 13.9 & 10 & $5134 \quad(5039-5230)$ & 7367 & 58.9 \\
\hline \multirow[t]{2}{*}{ Immediate treatment } & 3.8 & 2.57 & 3 & 13306 (13 199-13 413) & & \\
\hline & 3.8 & 2.57 & 10 & 12501 (12 417-12 586) & & \\
\hline \multicolumn{7}{|l|}{ First year and 10-year follow-up } \\
\hline \multirow[t]{2}{*}{ Active surveillance } & 3.8 & 13.9 & 3 & $9438 \quad$ (9 246-9 629) & 7601 & 44.6 \\
\hline & 3.8 & 13.9 & 10 & $7357 \quad$ (7 214-7 499) & 7239 & 49.6 \\
\hline \multirow[t]{2}{*}{ Immediate treatment } & 3.8 & 2.57 & 3 & 17039 (16 836-17 242) & & \\
\hline & 3.8 & 2.57 & 10 & 14596 (14 461-14 731) & & \\
\hline \multicolumn{7}{|l|}{$\begin{array}{l}\text { Model with } 15 \text { years of } \\
\text { follow-up }\end{array}$} \\
\hline \multirow[t]{2}{*}{ Active surveillance } & 3.8§; 8.16ף & 13.9 & - & 14806 (14 480-15 132) & 8063 & 35.3 \\
\hline & 3.8§; 8.16ף & 13.9 & 5 & 11082 (10 853-11 311) & 7013 & 38.8 \\
\hline \multirow[t]{2}{*}{ Immediate treatment } & $3.8 \S ; 8.16 \rrbracket$ & 2.57 & - & 22869 (22 511-23 227) & & \\
\hline & 3.8§; 8.16ף & 2.57 & 5 & 18095 (17 864-18 324) & & \\
\hline \multicolumn{7}{|c|}{$\begin{array}{l}\text { Note: } \mathrm{Cl}=\text { confidence interval. } \\
\text { *Yearly rate. } \\
+ \text { †The } 95 \% \mathrm{Cl} \text { of the mean cost was obtained by the simulation of } 1000 \text { samples of equal sample size of } 12750 \text { patients. } \\
\text { fThe assumptions are as follows: } 1 \text { ) } 2 \text { additional biopsies in the first } 5 \text {-year period of follow-up; } 2 \text { ) rate of death and rate of recurrence, both set to } 0 ; 3) \text { probability of } \\
\text { receiving each specific treatment assumed to be } 0.4 \text { for radical prostatectomy, } 0.25 \text { for intensity-modulated radiotherapy, } 0.1 \text { for intensity-modulated radiotherapy plus } \\
\text { androgen deprivation therapy, } 0.15 \text { for brachytherapy and } 0.1 \text { for androgen deprivation therapy; and } 4 \text { ) probability of receiving delayed treatment of } 7 \% \text { per year, in the first } \\
5 \text { years of follow-up, and } 4.5 \% \text { per year in the following } 5 \text {-year period. } \\
\text { \$Years } 1 \text { to } 10 \text {. } \\
\text { qYears } 11 \text { to } 15 .\end{array}$} \\
\hline
\end{tabular}

additional year of active surveillance, the mean cost of androgen deprivation therapy is considerably decreased with the delay of treatment initiation. In addition, Keegan and col-

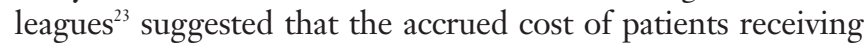
active surveillance undergoing delayed treatment are substantial, and have highlighted the importance of rapidly identifying those patients likely to need immediate treatment. Our results confirm that delayed treatment is associated with addi- tional costs in patients requiring immediate treatment, but this cost is minimal. The cost of treatments will increase between $3.3 \%$ and $6.7 \%$ per year; however, this increase will be entirely balanced by the $5 \%$ yearly discount rate of a delayed expense. In addition, when no additional clinical benefits are expected with an early initiation of androgen deprivation therapy, clinicians can be reassured that there is no economic reason for it. 
Four other studies have evaluated the cost of active surveillance and the cost of immediate treatment (i.e., radical prostatectomy, brachytherapy, intensity-modulated radiotherapy) with all but one reflecting US costs, which are considerably higher than Canadian costs. ${ }^{31-34}$ In addition, high variation has been observed across the US studies, mainly for the initial cost of treatments. Therefore, these estimates are higher in the study by Keegan and colleagues ${ }^{23}$ and correspond to 1.5 times the cost of brachytherapy and to 5.5 times the cost of active surveillance found by Eldefrawy and colleagues. ${ }^{31}$ Moreover, the only non-US evaluation of active surveillance cost was performed in Sweden and was compared with the cost of radical prostatectomy. ${ }^{34}$ These results showed that during a median follow-up of 12 years, the overall cost in the radical prostatectomy group was 34\% higher than in the active surveillance group, corresponding to a difference of $€ 6123 .^{34}$

\section{Limitations}

Our study presents some limitations. First, this economic evaluation was mainly based on costs derived from the Régie de l'assurance maladie du Québec's lists (billing manual and list of medications approved for public reimbursement). ${ }^{25,26}$ Although medication costs, professional fees and laboratory costs are generally similar across Canadian provinces, the medical fees and honoraria may be sometimes lower in Quebec. However, we presumed that these differences were minor and would not affect the generalizability of our results to other Canadian provinces. Second, although our model expands on the work of Keegan and colleagues ${ }^{23}$ by accounting for risk of death and recurrence requiring additional treatment, this model does not account for costs associated with adverse effects or complications related to treatments. Third, we considered treatment distribution to be constant over time. Even if the probability of receiving radiotherapy can increase with age, we believe the variation will be minimal in a population aged 65 years and older, and its impact on cost estimates will not be substantial. However, we have evaluated the effect of cost savings from active surveillance in the case when only $10 \%$ of patients could receive radical prostatectomy after 10 years of follow-up (41.6\% intensity-modulated radiotherapy, $16 \%$ intensity-modulated radiotherapy plus androgen deprivation therapy, 25\% brachytherapy and $7.4 \%$ androgen deprivation therapy). The corresponding cost benefits of active surveillance were even more important. The decrease in the percentage of patients receiving both radical prostatectomy and intensity-modulated radiotherapy (as primary treatment followed by salvage therapy) is likely to be the main factor explaining this situation.

\section{Conclusion}

Ten years after diagnosis of prostate cancer, active surveillance with delayed treatment had a lower cost than immediate treatment. With health care costs growing rapidly and access to innovative medicines being limited or restricted by public funding, it is desirable to find ways to increase efficiency. Furthermore, optimizing the management of low-risk prostate cancer could result in cost reallocation and maximization of health care services offered to patients with prostate cancer. The results of our study add to the economic rationale advocating active surveillance for eligible men with low-risk prostate cancer and highlights estimated cost savings specific to the Canadian health system.

\section{References}

1. Canadian Cancer Statistics 2011. Ottawa (ON): Statistics Canada. Available: www .cancer-asian.com/images/news/Canadian_Cancer\%20Statistics_2011_English.pdf (accessed 2012 June).

2. Cancer trends progress report - 2010/2011 update. Bethseda (MD): National Cancer Institute; 2006.

3. Fourcade RO, Benedict A, Black LK, et al. Treatment costs of prostate cancer in the first year after diagnosis: a short-term cost of illness study for France, Germany, Italy, Spain and the UK. B7U Int 2010;105:49-56.

4. Roehrborn CG, Black LK. The economic burden of prostate cancer. BJU Int 2011;108:806-13.

5. Grover SA, Coupal L, Zowall H, et al. The economic burden of prostate cancer in Canada: forecasts from the Montreal Prostate Cancer Model. CMAF. 2000;162:987-92.

6. Economic burden of illness in Canada, 1998. Ottawa (ON): Health Canada; 2002. Available: http://publications.gc.ca/collections/Collection/H21-136-1998E.pdf (accessed 2012 June).

7. Schröder FH, Hugosson J, Roobol MJ, et al. Prostate-cancer mortality at 11 years of follow-up. N Engl 7 Med 2012;366:981-90.

8. Andriole GL, Crawford ED, Grubb RL 3rd, et al. Prostate cancer screening in the randomized Prostate, Lung, Colorectal, and Ovarian Cancer Screening Trial: mortality results after 13 years of follow-up. 7 Natl Cancer Inst 2012;104:125-32.

9. Mohler J, Bahnson RR, Busby JE. NCCN clinical practice guidelines in oncology: prostate cancer. 7 Natl Compr Canc Netw 2010;8:162-200.

10. Wu JN, Dall'Era MA. Active surveillance for localized prostate cancer-current practices and recommendations. ScientificWorldfournal 2010;10:2352-61.

11. Klotz L, Zhang L, Lam A, et al. Clinical results of long-term follow-up of a large, active surveillance cohort with localized prostate cancer. 7 Clin Oncol 2010; 28:126-31.

12. Carlsson S, Aus G, Bergdahl S, et al. The excess burden of side-effects from treatment in men allocated to screening for prostate cancer. The Goteborg randomised population-based prostate cancer screening trial. Eur 7 Cancer 2011; 47:545-53.

13. Johansson E, Bill-Axelson A, Holmberg L, et al. Time, symptom burden, androgen deprivation, and self-assessed quality of life after radical prostatectomy or watchful waiting: the Randomized Scandinavian Prostate Cancer Group Study Number 4 (SPCG-4) clinical trial. Eur Urol 2009;55:422-30.

14. Thong MS, Mols F, Kil PJ, et al. Prostate cancer survivors who would be eligible for active surveillance but were either treated with radiotherapy or managed expectantly: comparisons on long-term quality of life and symptom burden. B7U Int 2010;105:652-8.

15. Hayes JH, Ollendorf DA, Pearson SD, et al. Active surveillance compared with initial treatment for men with low-risk prostate cancer: a decision analysis. 7AMA 2010;304:2373-80.

16. Sommers BD, Beard CJ, D'Amico AV, et al. Decision analysis using individual patient preferences to determine optimal treatment for localized prostate cancer. Cancer 2007;110:2210-7.

17. Prostate cancer: diagnosis and treatment. NICE clinical guideline 58. London (UK): National Institute for Health and Clinical Excellence;2008.

18. Cooperberg MR, Broering JM, Carroll PR. Time trends and local variation in primary treatment of localized prostate cancer. 7 Clin Oncol 2010;28:1117-23.

19. Crawford ED, Black L, Eaddy M, et al. A retrospective analysis illustrating the substantial clinical and economic burden of prostate cancer. Prostate Cancer Prostatic Dis 2010;13:162-7.

20. Krahn MD, Zagorski B, Laporte A, et al. Healthcare costs associated with prostate cancer: estimates from a population-based study. BfU Int 2010;105:338-46.

21. van Leeuwen PJ, Connolly D, Gavin A, et al. Prostate cancer mortality in screen and clinically detected prostate cancer: estimating the screening benefit. Eur 7 Cancer 2010;46:377-83.

22. Andriole GL, Crawford ED, Grubb RL III, et al. Mortality results from a randomized prostate-cancer screening trial. N Engl 7 Med 2009;360:1310-9.

23. Keegan KA, Dall'Era MA, Durbin-Johnson B, et al. Active surveillance for prostate cancer compared with immediate treatment: an economic analysis. Cancer 2012:118:3512-8.

24. Akobundu E, Ju J, Blatt L, et al. Cost-of-illness studies: a review of current methods. Pharmacoeconomics 2006;24:869-90.

25. Manuel des médecins spécialistes. Québec (QC): Régie de l'assurance maladie du Québec; 2012. Available: www.ramq.gouv.qc.ca/fr/professionnels/medecinsspecialistes/manuels/Pages/facturation.aspx (accessed 2012 June).

26. Manuel des pharmaciens. Québec (QC): Régie de l'assurance maladie du Québec; 2012. Available: www.ramq.gouv.qc.ca/fr/professionnels/pharmaciens/manuels /Pages/manuel-pharmaciens.aspx (accessed 2012 June).

27. Ministère de la Santé et des Services sociaux. Performance hospitalière (APR- 
DRG (J57)). Available: www.informa.msss.gouv.qc.ca/Details.aspx?Id=SD+eml WTaZk $=\&$ Source $=/ \mathrm{dlVmYIVYBQ}=($ accessed $2012 \mathrm{June})$.

28. Brachytherapy and prostate cancer: Montréal (QC): Conseil d'évaluation des technologies de la santé du Québec (CETS); 2000.

29. Canadian Patient Cost Database (CPCD) metadata. Ottawa (ON): Canadian Institute for Health Information; 2011. Available: www.cihi.ca/CIHI-ext-portal /internet/en/document/spending+and+health+workforce/spending/spending+by +geography/cped_metadata (accessed 2012 June).

30. Drummond MF, Sculpher MJ, Torrance G. Methods for the economic evaluation of bealth care programmes, third edition. New York (NY): Oxford University Press; 2005.

31. Eldefrawy A, Katkoori D, Abramowitz M, et al. Active surveillance vs. treatment for low-risk prostate cancer: a cost comparison. Urol Oncol 2013;31:576-80.

32. Corcoran AT, Peele PB, Benoit RM. Cost comparison between watchful waiting with active surveillance and active treatment of clinically localized prostate cancer. Urology 2010;76:703-7.

33. Wilson LS, Tesoro R, Elkin EP, et al. Cumulative cost pattern comparison of prostate cancer treatments. Cancer 2007;109:518-27.

34. Andersson SO, Andren O, Lyth J, et al. Managing localized prostate cancer by radical prostatectomy or watchful waiting: cost analysis of a randomized trial (SPCG-4). Scand 7 Urol Nephrol 2011;45:177-83.
Affiliations: Department of Surgery (Dragomir, Aprikian), Division of Urology, McGill University; Research Institute of the McGill University Health Centre (Dragomir, Aprikian); McGill University Health Centre (Cury, Aprikian); Department of Oncology (Cury), Division of Radiation Oncology, McGill University, Montréal, Que.

Contributors: Alice Dragomir and Armen Aprikian designed the study. The models were developed by Alice Dragomir with the collaboration of Armen Aprikian and Fabio Cury. Alice Dragomir drafted the manuscript. All of the authors revised the manuscript and approved the final version submitted for publication.

Acknowledgements: The authors thank the Coté Sharp Family Foundation for its financial contribution to the Program in Health Economics of Prostate Cancers at McGill University's Division of Urology.

Supplemental information: For reviewer comments and the original submission of this manuscript, please see www.cmajopen.ca/content/2/2 /E60/suppl/DC1 